\title{
Journal of Advanced Research in Fluid
} Mechanics and Thermal Sciences

\section{Nanofluid as an Alternative Coolant in Machining: A Review}

\author{
Kumaran Kadirgama ${ }^{1, *}$ \\ Faculty of Mechanical \& Automotive Engineering Technology, Universiti Malaysia Pahang, Malaysia
}

\begin{tabular}{|c|c|}
\hline ARTICLE INFO & ABSTRACT \\
\hline $\begin{array}{l}\text { Article history: } \\
\text { Received } 31 \text { December } 2019 \\
\text { Received in revised form } 1 \text { February } 2020 \\
\text { Accepted } 1 \text { February } 2020 \\
\text { Available online } 9 \text { April } 2020\end{array}$ & $\begin{array}{l}\text { This review paper is concerned about the important of nanofluid in machining. It is } \\
\text { discussed in several parts such as cutting force, surface roughness, tool life and tool } \\
\text { wear. Various type of nanofluid is discussed in this paper with an effect on the surface } \\
\text { roughness, force, tool life, and wear. Nanofluid plays a significant role in the increment } \\
\text { of tool life and reducing tool wear. Nanofluid creates an artificial layer on top of the } \\
\text { workpiece, and this reduces wear at the cutting tool. It seems that nanofluid can be } \\
\text { the next alternative coolant in machining. }\end{array}$ \\
\hline
\end{tabular}

Keywords:

Nanofluid; machining; wear; tool life

Copyright @ 2020 PENERBIT AKADEMIA BARU - All rights reserved

\section{Introduction}

Machining plays major role in the manufacturing industry because machining is used to produce desired shape, size and surface finish through the removal of excess materials in the form of small chips. In machining operations, cutting tools are used to remove the excess material to produce the desired product [1]. The machine tool gives necessary relative motion during the machining process. The temperature rises due to the direct mechanical contact between the workpiece and cutting tool during machining will reduce the tool strength. Hence it will lead to a faster tool failure and wear $[2,3]$. To produce at higher rate, high cutting speed is needed but it also will lead to a faster tool wear. To prevent the tool wear take place in a faster rate, the temperature should be controlled during machining. It is also important to reduce the heat produced during machining to avoid the cutting tool lose its sharpness and cause poor surface finish. The tool life also will be shortened if the excessive heat is not controlled. Thus, the usage of cutting fluid is essential to reduce the heat produced at the tool and work piece interface for a better surface finish, enhance the tool life and reduce the tool wear with a reduction in cutting force.

The cutting fluid plays important role in removing the heat generated from friction between cutting tool and workpiece which will eventually reduce temperature rise in cutting tool. Cutting tool's life span will be prolonged by lowering the heat generated at tool-workpiece interface during

\footnotetext{
* Corresponding author.

E-mail address: kumaran@ump.edu.my (Kumaran Kadirgama)
} 
machining. The cutting fluid will dissipate the heat produced at the interface surface area and lower the friction force between the tool and workpiece. Chis deformation and high thermal load which cause tool wear to occur mainly developed by the friction force. To reduce the friction force the cutting force should be reduced during machining process and it will prolong the life span of the cutting tool [4-6]. During cutting process, the tool wear occur especially at the edge of cutting tool [7]. The wear formation at the cutting tool results in poor surface finish and product with less dimensional accuracy. Cutting fluid also helps to prevent the formation of Build-up edge (BUE) and Build-up layer (BUL) defects which causes bad appearance on the workpiece. Other than that, cutting fluid also used to wash away chips during machining.

Many researchers have conducted various researches on alternating the cutting fluid as coolant. Most of the investigation of alternating the cutting fluid is mainly focused on minimum quantity lubricant technique and there are very few research and publication about using nanofluid as coolant [8]. On the other hand, it is reported that the dispersed nanoparticle additives ( $\mathrm{TiO}_{2}, \mathrm{ZnO}$, SiC, etc) in the based liquid exhibits higher load carrying capacity, anti-wear and friction reduction properties [9] Therefore, these features can make the nanofluid very attractive in usage of machining coolant.

The concept of nanocoolant or nanofluid is referred to dispersions of nano particle into the based liquid which is water or ethylene glycol $[10,11]$. Nanofluids are the next generation heat transfer fluid due to their higher thermal conductivity than those of based liquid [12-14]. From the viewpoints hybrid nanofluid show better performance in term of heat transfer rate, compare to conventional coolant for machining. Besides that, the cutting temperature could also be reduced in both workpiece and cutting tools due to its high heat transfer rate $[15,16]$. Therefore, the tool life and the surface integrity considered to be much improved compared with normal commercial coolant [17].

\section{Cutting Force}

The main objective of machining process is to obtain a good quality and cheap parts. The power consumption will rise when the cutting forces rise thus the machining costs also increase. Various researches reported that by adding the nanoparticles into coolant the cutting force reduced dramatically. Table 1 shows the percentage of reduction in cutting force when using nanofluids as cutting fluid. Through many literature reviews, it found out that the nanofluids tends to reduce the cutting force by reducing the friction between the surfaces in contact [18].

According to Padmini et al., and Singh et al., viscosity also plays some role which influences the reduction in cutting force $[19,20]$. The authors stated that the dissipation capacity of nanofluid tends to increase when the viscosity is low. If the viscosity is high, the nanofluid is able to form a consistent barrier which will separate both the surfaces in contact during machining $[18,21]$ also agree that there will be a layer formed which act as a barrier that reducing the cutting force. Due to the barrier, the friction between the surfaces in contact and the cutting forces reduce simultaneously [19]. Reddy and Rao mentioned that the specific energy of the nanoparticles is effective in reducing the frictional forces between the tool and workpiece which leads to reduction in cutting force [22].

Raju et al., and Sahu et al., reported that the nanofluid improved lubricant properties leads to a high wettability and enables to lubricate the cutting zone much better while resulting in lesser frictional force $[23,24]$. According to Lee et al., and Zhou et al., nanofluids tends to reduce the cutting force due to its friction coefficient which evaluate the characteristics of a lubricant $[25,26]$. Khandekar et al., stated that nanofluid reduce the cutting force magnitude better than conventional cutting fluid due to the enhanced cooling characterization [27].

According to Khrisna, nanofluid act as a film that reduce the coefficient friction between toolworkpiece interface which lead to reduction in cutting force [28]. Yuan et al., stated that the larger 
surface area of diamond made the surface contact area flatter and lower the cutting force generated. They also mentioned that the larger the surface area of a nanoparticle the more effective it will be in reducing the cutting force [29].

Table 1

Reduction in cutting force when using different nanofluids

\begin{tabular}{|c|c|c|}
\hline Authors & Cutting Fluid & Reduction in Cutting Force \\
\hline [19] & Coconut oil (CC) + nano molybdenum disulphide $\left(\mathrm{nMoS}_{2}\right)$ & 37 percentage of reduction \\
\hline$[20]$ & Alumina based fluid with graphene nano plates & $9.94 \%$ reduction in cutting force \\
\hline$[22]$ & Graphite, Molybdenum disulphide $\left(\mathrm{MoS}_{2}\right)$ & $\begin{array}{l}20 \% \text { of reduction for graphite powder and } 28 \% \\
\text { reduction for } \mathrm{MoS}_{2} \text { powder. }\end{array}$ \\
\hline [23] & $\begin{array}{l}\text { Multi wall carbon nanotubes and distilled water with } \\
\text { sodium dodecyl sulphate as surfactant }\end{array}$ & 5 to 8 percentage reduction \\
\hline$[25]$ & Mineral oil with graphite nanoparticle & $24 \%$ of reduction \\
\hline [27] & Aluminum Oxide added to the conventional cutting fluid & $50 \%$ of reduction \\
\hline$[26]$ & $\mathrm{Fe}_{3} \mathrm{O}_{4}$ with conventional coolant & $38.4 \%$ reduction \\
\hline [28] & Nano boric Acid with coconut oil & $14.5 \%$ reduction than dry machining \\
\hline [30] & $\mathrm{Al}_{2} \mathrm{O}_{3}$ with carbon nanotube (CNT) in vegetable oil & $11.8 \%$ reduction \\
\hline$[24]$ & MWCNT nanofluid with distilled water & $28 \%$ drop of cutting force \\
\hline [29] & Natural777 oil based diamond nanoparticle & $10.71 \%$ \\
\hline
\end{tabular}

\section{Surface Roughness}

In machining process achieving a desired surface quality is very important. The desired surface index of product quality basically called surface roughness which is a technical requirement for most of the mechanical products [31]. To achieve a fine surface roughness the friction and heat generated between the surface contacts reduced by using cutting fluids. By using nanofluid as a replacement for conventional cutting fluid, the quality of product increased by reducing the surface roughness of the product. Table 2 shows the surface roughness reduction when using different nanofluids.

Vasu and Kumar stated that the generated intensive temperature at the workpiece surface will increase the residual stress and lead to micro cracking of the work piece [32]. By adding $\mathrm{Al}_{2} \mathrm{O}_{3}$ nanoparticles the stress at workpiece surface area decreases and produces a fine surface roughness. Sharma et al., stated that nano fluid produces lowest surface roughness because the nanoparticles within the nanofluid enhance the heat dissipation and improve the properties of the tool's rake face [33]. Hence it will lead to a smoother machining process and retain the tool's hardness and sharpness. Sharma et al., mentioned that Multi wall carbon nanotube (MWCNT) nanoparticles act as a layer which reduces the heat generated at the cutting zone [34]. They also stated that other than providing a good surface roughness MWCNT also reduce tool wears.

Roy and Ghosh reported that the high temperature caused by the high velocities is reduced greatly by adding nanoparticles into cutting fluid due to the thermal properties of the nanoparticles [35]. According to Kadirgama et al., nanofluid is considered as higher heat transfer fluid due to their improved thermal conductivity [36]. Zhou et al., also share same opinion that the thermal conductivity enhancement helps to reduce the heat generated and also, act as a heat transfer medium and dissipate the heat generated at the cutting tool interphase [26]. Therefore, less burning occurs at the cutting zone and enhance the surface quality of the workpiece.

Sharma et al., mentioned that the $\mathrm{TiO}_{2}$ nanofluid enhances the wetting and lubricating properties of the rake face which retain the sharpness and hardness of the cutting tool for a longer period [33]. Gupta et al., stated that graphite nanofluid produce better surface roughness than aluminum oxide nanofluid due to the better thermal conductivity properties of graphite than aluminum oxide [37]. According to them, by achieving a fine surface quality the tool wears can be reduced drastically. Jamil 
et al., mentioned that the reduction in surface roughness is due to the better wetting properties of nanofluid at the workpiece and tool intact surface area [30].

According to Kulkarni et al., and Mahadi et al., the temperature reduce at the tool interface is reduce due to the rolling action of the billions of nanoparticles that contributes to the heat dissipation $[38,39]$. They also mentioned that thermal conductivity enhancement helps the nanofluid to perform better as heat transfer medium. Khrisna stated that the nanofluid provide a better surface roughness by reducing the coefficient friction which lead to reduction in cutting temperature [28].

Table 2

Reduction in surface roughness when using different nanofluids

\begin{tabular}{|c|c|c|}
\hline Authors & Cutting Fluid & Reduction in Surface roughness \\
\hline [32] & $\mathrm{Al}_{2} \mathrm{O}_{3}$ nanoparticles & $20-30 \%$ surface roughness reduction \\
\hline [33] & Aluminum oxide $\left(\mathrm{Al}_{2} \mathrm{O}_{3}\right)$ with vegetable oil & $47.8 \%$ reduction \\
\hline [34] & MWCNT with SAE oil & Better surface reduction than conventional coolant \\
\hline [35] & $\begin{array}{l}\text { Multi wall carbon nanotube (MWCNT) } \\
\text { with deionized water }\end{array}$ & $30-35 \%$ reduction \\
\hline [36] & Ethylene glycol (EG) with nanocellulose & $0.251-0.984 \mu \mathrm{m}$ \\
\hline [40] & Titanium dioxide $\left(\mathrm{TiO}_{2}\right)$ with vegetable oil & $34.7 \%$ reduction \\
\hline [37] & $\begin{array}{l}\text { Aluminum oxide/vegetable oil and } \\
\text { graphite/vegetable oil }\end{array}$ & $\begin{array}{l}\text { Graphite/vegetable oil give much better surface roughness } \\
\text { than aluminum oxide/vegetable oil }\end{array}$ \\
\hline$[30]$ & $\begin{array}{l}\mathrm{Al}_{2} \mathrm{O}_{3} \text { with carbon nanotube (CNT) in } \\
\text { vegetable oil }\end{array}$ & $8.72 \%$ reduction \\
\hline [26] & $\mathrm{Fe}_{3} \mathrm{O}_{4}$ with conventional coolant & $27.75 \%$ reduction \\
\hline [38] & Copper coated $\mathrm{Al}_{2} \mathrm{O}_{3}$ with distilled water & $\begin{array}{l}\text { Surface roughness improved better than conventional } \\
\text { coolant }\end{array}$ \\
\hline [39] & Boric acid with vegetable oil & $7.21 \%$ surface roughness enhancement \\
\hline [28] & Nano boric Acid with coconut oil & $24.74 \%$ enhancement than dry machining \\
\hline
\end{tabular}

\section{Tool Life}

Tool life is usually depending on tool wear [41]. The longer the tool can withstand the wear the longer the tool life span will be [42]. Tool life also can be increased by reducing the coefficient friction occurs between tool-workpiece interface area [43]. Even tough conventional coolant helps to reduce the heat generated at intact surface area, many research has been done to improve the thermal properties of the conventional coolant. Table 3 shows the tool life enhancement when using different nanofluids.

Vázquez et al., mentioned that by adding the nanoparticles into the conventional cutting fluid, their thermal properties enhanced and increase the tool life [44]. Minh et al., stated that the main reason for the tool life prolonged is due to the oil mist and the number of nanoparticles formed on flank face [45]. The formed oil mist and nanoparticles in the cutting zone increases to create "roller effect" which eventually reduce the cutting force and tool wear. According to Sharma et al., the hybrid nanofluid able to maintain the hardness of the tool longer due to their wettability while extracting heat from the tool at high rate [46].

Lü et al., reported that due to the better wettability, better lubrication, higher stability, and higher heat dissipation characterization of $\mathrm{TiO}_{2}$ nanofluid, increases the tool life $70 \%$ more than water [47]. Jamil et al., stated that the reduction in cutting temperature at tool-workpiece surface will increase the tool life. Due to the enhanced heat transfer properties of nanofluid the cutting temperature reduced drastically and prolong the tool life [30]. Eltaggaz et al., mentioned that the nanofluid penetrate in between the tool-workpiece surface area to form as a film that reduce the coefficient 
friction [48]. They also stated that the higher the thickness of the film the more it will reduce the heat generated and prolong the tool life.

According to Singh et al., the reduction in cutting force and cutting temperature leads to tool life enhancement [49]. They stated that when the heat generated at tool-workpiece interface is reduced the tool will be preserved from damaged. Muthusamy et al., found significant improvement in tool life in their research when using nanofluid [50]. They stated that the improvement is due to the excellent performance of nanofluid as heat transfer medium at tool-workpiece interface.

Table 3

Tool life enhancement when using different nanofluids

\begin{tabular}{|c|c|c|}
\hline Authors & Cutting Fluid & Tool life enhancement \\
\hline [44] & CuO nanoparticles with mineral oil & Increase the service life of the cutting tool up to $604 \%$ \\
\hline [45] & $\mathrm{Al}_{2} \mathrm{O}_{3}$ with soybean oil & Increase almost $177 \%$ of the tool life than base fluid \\
\hline [46] & $\begin{array}{l}\mathrm{Al}_{2} \mathrm{O}_{3} / \mathrm{MWCNT} \text { hybrid nano fluid with } \\
\text { vegetable oil }\end{array}$ & $\begin{array}{l}\text { Improved the tool life much more better than base fluid and } \\
\text { single nanofluid }\left(\mathrm{Al}_{2} \mathrm{O}_{3}\right)\end{array}$ \\
\hline [47] & $\mathrm{TiO}_{2}$ with deionized water & $70 \%$ more tool life than water \\
\hline [30] & $\begin{array}{l}\mathrm{Al}_{2} \mathrm{O}_{3} \text { with carbon nanotube (CNT) in } \\
\text { vegetable oil }\end{array}$ & $23 \%$ enhancement \\
\hline [48] & $\mathrm{Al}_{2} \mathrm{O}_{3}$ with vegetable oil & $23.5 \%$ enhancement in tool life \\
\hline [49] & Graphene with vegetable oil & $178-190 \%$ of tool life enhancement \\
\hline [50] & Ethylene glycol based $\mathrm{TiO}_{2}$ & Tool life is 54.9 minutes. \\
\hline
\end{tabular}

\section{Tool Wear}

Tool wear is mainly dependent on cutting conditions [51]. When there is much heat generated at tool-workpiece interface area the tool tends to lose its hardness and leading to wear at faster rate [52]. The wear criteria normally set at $0.3 \mathrm{~mm}$ as worn tool [50]. There are a lot of wear types that occurs during machining for example notch wear, comb crack, crater wear and chipping wear [5355]. But the major wear frequently occur is the flank wear [56]. To minimize the tool wear, many researches has been conducted on nanofluid to enhance the thermal properties. Table 4 shows the tool wears reduction when using nanofluid.

Zhou et al., mentioned that the nanofluid act as a lubricant that smooth the surface of the rake face during machining process [26]. The author also reported that less adhesion occurs when using nanofluid which leads to a high resistance towards the tool wear. Jamil et al., reported that the nanofluid reduce the heat from the primary shearing zone at faster rate and preventing the workpiece hardening [30]. Therefore the cutting tool can sustain longer the hardness of the workpiece and prevent the tool wear occurs at faster rate.

Sahu et al., mentioned that high surface area of the MWCNT; results in high heat transfer rate that helps to tool wear reduction [24]. The author also stated that even at low particle concentration the nanofluids are better as heat transfer fluid. Eltaggaz et al., stated that a mist composed nanoparticle and base fluid mist is created into tool-workpiece interface zone and forms a tribofilm [48]. The heat generated reduced significantly by the tribofilm as well as minimizing the coefficient friction that occurs at interface zone. Thus, the tool hardness able to withstand for a longer period and prevent tool wear to occur faster.

Das et al., in their research work; they compared $\mathrm{ZnO}, \mathrm{CuO}, \mathrm{Fe}_{2} \mathrm{O}_{3}$ and $\mathrm{Al}_{2} \mathrm{O}_{3}$, nanofluids to measure the reduction in tool wear [57]. They found out that the crater wear occur more in $\mathrm{Al}_{2} \mathrm{O}_{3}$ nanofluid than $\mathrm{CuO}$ nanofluid due to the high percentage of oxygen presence in $\mathrm{Al}_{2} \mathrm{O}_{3}$. The presence of high percentage of oxygen in $\mathrm{Al}_{2} \mathrm{O}_{3}$ caused significant weight percentage found during machining process and leads to improper cooling thus, crater wear and flank wear take place faster. According 
Das et al., CuO nanofluid has superior behavior compared to the other nanofluids while $\mathrm{Al} 2 \mathrm{O} 3$ nanofluid was last in the row [57].

\section{Table 4}

Tool wears reduction when using different nanofluids

\begin{tabular}{|c|c|c|}
\hline Authors & Cutting Fluid & Tool wear type/reduction \\
\hline$[26]$ & $\mathrm{Fe}_{3} \mathrm{O}_{4}$ with conventional coolant & Crack wear on rake face, wear resistance up to $63.3 \%$ \\
\hline$[30]$ & $\begin{array}{l}\mathrm{Al}_{2} \mathrm{O}_{3} \text { with carbon nanotube (CNT) in vegetable } \\
\text { oil }\end{array}$ & Flank wear occurs after 292 seconds of machining \\
\hline$[24]$ & MWCNT nanofluid with distilled water & $\begin{array}{l}\text { Average flank wear occurs at cutting length of } 960 \\
\mathrm{~mm}\end{array}$ \\
\hline$[48]$ & $\mathrm{Al}_{2} \mathrm{O}_{3}$ with vegetable oil & Up to $26.5 \%$ of flank wear reduced \\
\hline$[57]$ & $\mathrm{ZnO}, \mathrm{CuO}, \mathrm{Fe}_{2} \mathrm{O}_{3}$ and $\mathrm{Al}_{2} \mathrm{O}_{3}$, with distilled water & Crater wear and flank wear reduced \\
\hline$[50]$ & Ethylene glycol based $\mathrm{TiO}_{2}$ & Flank wear occurs after $940 \mathrm{~mm}$ cut length \\
\hline
\end{tabular}

\section{Morphology Analysis}

Figure 1 shows the nanofluid forming a thermal barrier between chip and cutting tool. According to Kadirgama et al., the small chip shows the presence of less aluminum percentage proves that the nanofluid is capable to carry away the heat generated due to the superior thermal conductivity properties [36]. They also mentioned that carbon element presence in the nanofluid embedded the chip surfaces and act as a thermal barrier which reduce thermal expansion greatly.

Figure 2 shows the flank wear occurs at faster rate when using the conventional cutting coolant. Muthusamy et al., found that at the $720 \mathrm{~mm}$ cut length the cutting tool using nanofluid still with stand the heat generated while conventional cutting fluid couldn't withstand the heat and lead to tool wear [50]. Thamizhmanii and Hasan also mentioned in their research work that flank wear is highly affected by the high heat generated on the flank wear [58]. Khandekar et al., mentioned that the nanofluid has improved conduction, convection and wettability compare to the conventional cutting fluid [27]. The superior properties of the nanofluid make them to withstand the high temperature at a longer period of time [59].

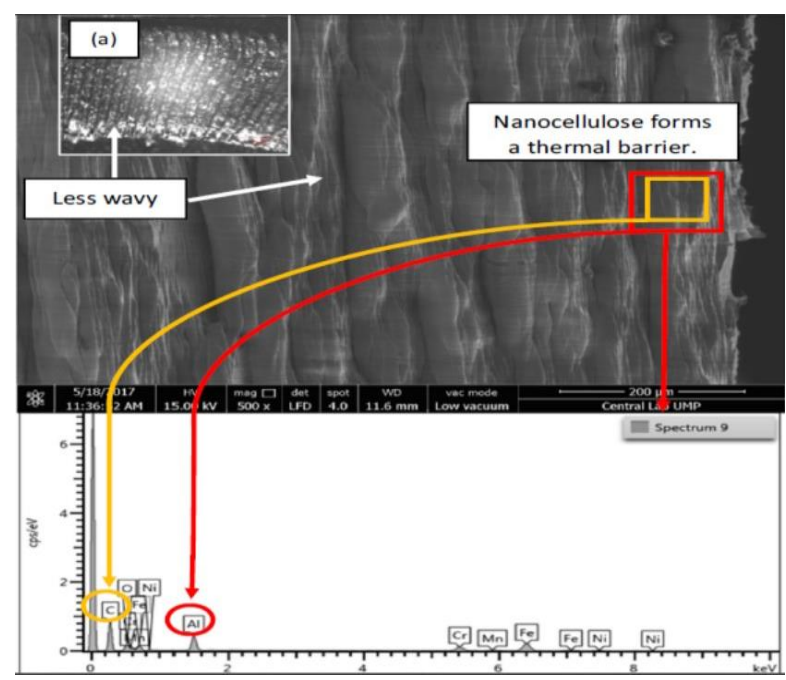

Fig. 1. Thermal barrier formed by nanofluid [36] 

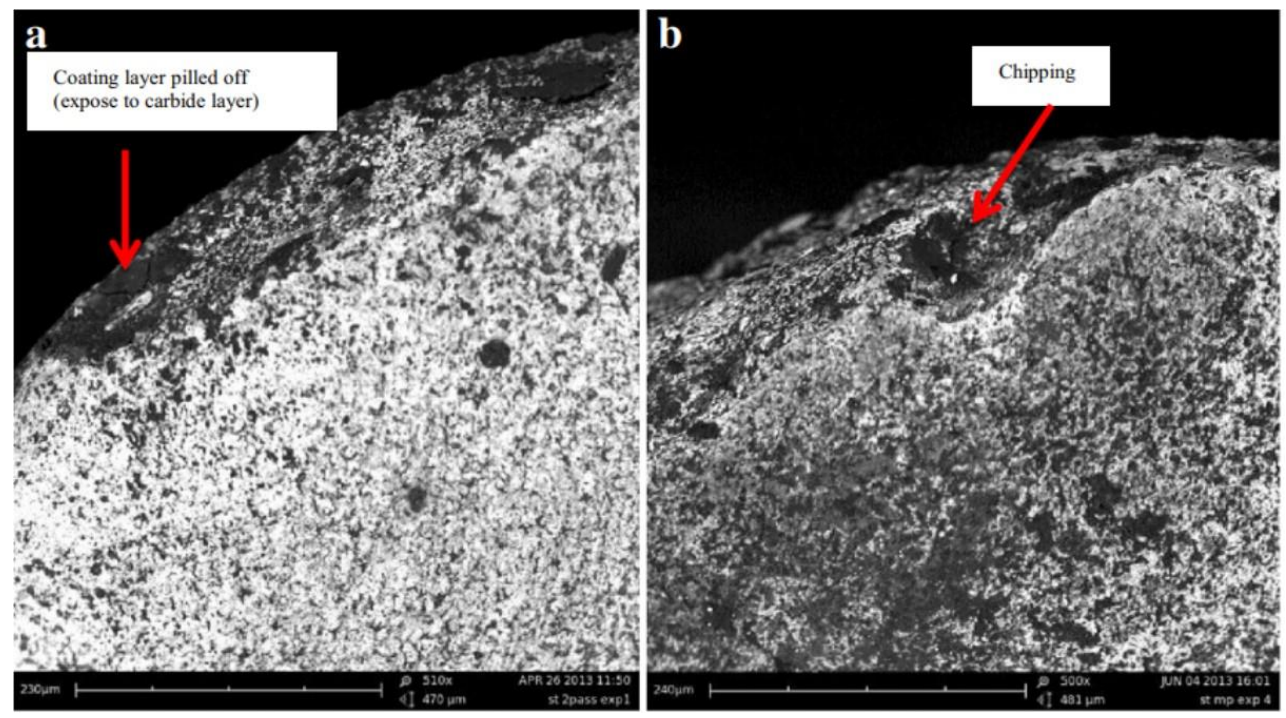

Fig. 2. SEM images after cut length of $720 \mathrm{~mm}$ with a) nanofluid and b) conventional cutting coolant [50]

\section{Costing Analysis}

The innovation and development of machining triggered research on machining with minimum energy consumption and production at lowest cost [60]. Conventional cutting fluid replaced with nanofluid is one of the steps to reduce the machining cost. Cutting fluid mainly used to and to lubricate. According to Krajnik et al., limiting the usage of coolant in machining will reduces machining costs [61]. Apart from that the usage of cutting fluids range from $7-17 \%$ of the total costs of the manufactured workpiece [62]. According to Abbas et al., the cost of machining $100 \mathrm{~mm}$ distance using conventional cutting fluid is about $\$ 2.170$ while nanofluid cost $\$ 2.306$ for the same distance [60]. The author also mentioned that even though nanofluid is costing a bit higher, but when comparing with the sustainability assessment the nanofluid cost lower than conventional coolant.

\section{Conclusions}

From the reviews, the following conclusions can be summarized

i. Nanofluid improved lubricant properties leads to a high wettability and enables to lubricate the cutting zone much better while resulting in lesser frictional force. Reduced frictional force resulting in reduction of cutting force.

ii. Nanofluid produces lowest surface roughness because the nanoparticles within the nanofluid enhance the heat transfer and improve the properties of the tool's rake face. Hence it will lead to a smoother machining process and retain the tool's hardness and sharpness.

iii. Nanofluid prolongs the tool life due to the oil mist and the number of nanoparticles formed on flank face. The formed oil mist and nanoparticles in the cutting zone increases to create a film of barrier which eventually reduce the cutting force and tool wear.

iv. Nanofluid reduces tool wear by reducing the heat from the primary shearing zone at faster rate and preventing the workpiece hardening. Thus, the cutting tool can sustain longer the hardness of the workpiece and prevent the tool wear occurs at faster rate. 


\section{Acknowledgement}

The authors express their grateful appreciation to the University Malaysia Pahang for providing laboratory facilities and financial assistance under project no RDU1803136 and RDU190351.

\section{References}

[1] Nagasasikala, Madduleti, and G. Phrabhakar Rao. "Heat and mass transfer of a MHD flow of a nanofluid through a porous medium in an annular, circular region with outer cylinder maintained at constant heat flux." In NCIT Conference, SSBN Degree College, Ananatapuramu. 2016.

[2] Bruni, C., A. Forcellese, F. Gabrielli, and M. Simoncini. "Effect of the lubrication-cooling technique, insert technology and machine bed material on the workpart surface finish and tool wear in finish turning of AISI 420B." International Journal of Machine Tools and Manufacture 46, no. 12-13 (2006): 1547-1554. https://doi.org/10.1016/j.ijmachtools.2005.09.007

[3] Turkyilmazoglu, Mustafa. "A note on the correspondence between certain nanofluid flows and standard fluid flows." Journal of Heat Transfer 137, no. 2 (2015).

https://doi.org/10.1115/1.4028807

[4] Samylingam, L., K. Anamalai, K. Kadirgama, M. Samykano, D. Ramasamy, M. M. Noor, G. Najafi, M. M. Rahman, Hong Wei Xian, and Nor Azwadi Che Sidik. "Thermal analysis of cellulose nanocrystal-ethylene glycol nanofluid coolant." International Journal of Heat and Mass Transfer 127 (2018): 173-181.

https://doi.org/10.1016/i.ijheatmasstransfer.2018.07.080

[5] Turkyilmazoglu, Mustafa. "Flow of nanofluid plane wall jet and heat transfer." European Journal of MechanicsB/Fluids 59 (2016): 18-24.

https://doi.org/10.1016/i.euromechflu.2016.04.007

[6] Turkyilmazoglu, Mustafa. "Buongiorno model in a nanofluid filled asymmetric channel fulfilling zero net particle flux at the walls." International Journal of Heat and Mass Transfer 126 (2018): 974-979. https://doi.org/10.1016/i.ijheatmasstransfer.2018.05.093

[7] Schuldt, S., G. Arnold, J. Kowalewski, Y. Schneider, and H. Rohm. "Analysis of the sharpness of blades for food cutting." Journal of Food Engineering 188 (2016): 13-20.

https://doi.org/10.1016/j.jfoodeng.2016.04.022

[8] Yazid, M. Z. A., C. H. CheHaron, J. A. Ghani, G. A. Ibrahim, and A. Y. M. Said. "Surface integrity of Inconel 718 when finish turning with PVD coated carbide tool under MQL." Procedia Engineering 19 (2011): 396-401.

https://doi.org/10.1016/j.proeng.2011.11.131

[9] Murshed, S. M. S., K. C. Leong, and C. Yang. "Investigations of thermal conductivity and viscosity of nanofluids." International Journal of Thermal Sciences 47, no. 5 (2008): 560-568. https://doi.org/10.1016/j.ijthermalsci.2007.05.004

[10] S. B. Abubakar, N. A. Che Sidik, and A. S. Ahmad. "The use of Fe3O4-H2O4 nanofluid for heat transfer enhancement in rectangular microchannel heatsink." Journal of Advanced Research in Materials Science 23, no. 1 (2016): 15-24.

[11] Muhammad Nura Mu'az, Nor Azwadi Che Sidik, Aminuddin Saat, and Bala Abdullahi. "Effect of Nanofluids on Heat Transfer and Pressure Drop Characteristics of Diverging-Converging Minichannel heat sink." CFD Letters 11, no. 4 (2019): 105-120.

[12] Lee, S., SU-S. Choi, S, and Li, and J. A. Eastman. "Measuring thermal conductivity of fluids containing oxide nanoparticles." Journal of Heat Transfer (1999): 280-289. https://doi.org/10.1115/1.2825978

[13] Turkyilmazoglu, Mustafa. "Free and circular jets cooled by single phase nanofluids." European Journal of Mechanics-B/Fluids 76 (2019): 1-6.

https://doi.org/10.1016/j.euromechflu.2019.01.009

[14] Turkyilmazoglu, Mustafa. "Fully developed slip flow in a concentric annuli via single and dual phase nanofluids models." Computer methods and programs in biomedicine 179 (2019): 104997. https://doi.org/10.1016/j.cmpb.2019.104997

[15] Hong, W. X., NA Che Sidik, and M. Beriache. "Heat transfer performance of hybrid nanofluid as nanocoolant in automobile radiator system." Journal of Advanced Research Design 51 (2018): 14-25.

[16] Lee, Y. K. "The use of nanofluids in domestic water heat exchanger." J. Adv. Res. Appl. Mech 3, no. 1 (2014): 9-24.

[17] Sarkar, Jahar, Pradyumna Ghosh, and Arjumand Adil. "A review on hybrid nanofluids: recent research, development and applications." Renewable and Sustainable Energy Reviews 43 (2015): 164-177. https://doi.org/10.1016/i.rser.2014.11.023

[18] Sivashanmugam, P. "Application of nanofluids in heat transfer." An overview of heat transfer phenomena 16 (2012). https://doi.org/10.5772/52496 
[19] Padmini, R., P. Vamsi Krishna, and G. Krishna Mohana Rao. "Effectiveness of vegetable oil based nanofluids as potential cutting fluids in turning AISI 1040 steel." Tribology International 94 (2016): 490-501. https://doi.org/10.1016/i.triboint.2015.10.006

[20] Singh, Rabesh Kumar, Anuj Kumar Sharma, Amit Rai Dixit, Arun Kumar Tiwari, Alokesh Pramanik, and Amitava Mandal. "Performance evaluation of alumina-graphene hybrid nano-cutting fluid in hard turning." Journal of cleaner production 162 (2017): 830-845. https://doi.org/10.1016/i.jclepro.2017.06.104

[21] Turkyilmazoglu, Mustafa. "Single phase nanofluids in fluid mechanics and their hydrodynamic linear stability analysis." Computer Methods and Programs in Biomedicine 187 (2020): 105171.

https://doi.org/10.1016/i.cmpb.2019.105171

[22] Reddy, N. Suresh Kumar, and P. Venkateswara Rao. "Experimental investigation to study the effect of solid lubricants on cutting forces and surface quality in end milling." International Journal of Machine Tools and Manufacture 46, no. 2 (2006): 189-198. https://doi.org/10.1016/j.ijmachtools.2005.04.008

[23] Raju, Roja Abraham, Atul Andhare, and Neelesh Kumar Sahu. "Performance of multi-walled carbon nanotube-based nanofluid in turning operation." Materials and Manufacturing Processes 32, no. 13 (2017): 1490-1496. https://doi.org/10.1080/10426914.2017.1279291

[24] Sahu, Neelesh Kumar, Atul B. Andhare, and Roja Abraham Raju. "Evaluation of performance of nanofluid using multiwalled carbon nanotubes for machining of Ti-6AL-4V." Machining Science and Technology 22, no. 3 (2018): 476-492. https://doi.org/10.1080/10910344.2017.1365898

[25] Lee, Chang-Gun, Yu-Jin Hwang, Young-Min Choi, Jae-Keun Lee, Cheol Choi, and Je-Myung Oh. "A study on the tribological characteristics of graphite nano lubricants." International journal of precision engineering and manufacturing 10, no. 1 (2009): 85-90. https://doi.org/10.1007/s12541-009-0013-4

[26] Zhou, Chichi, Xuhong Guo, Kedong Zhang, Li Cheng, and Yongqiang Wu. "The coupling effect of micro-groove textures and nanofluids on cutting performance of uncoated cemented carbide tools in milling Ti-6Al-4V." Journal of Materials Processing Technology 271 (2019): 36-45.

https://doi.org/10.1016/j.jmatprotec.2019.03.021

[27] Khandekar, S., M. Ravi Sankar, V. Agnihotri, and J. Ramkumar. "Nano-cutting fluid for enhancement of metal cutting performance." Materials and Manufacturing Processes 27, no. 9 (2012): 963-967.

https://doi.org/10.1080/10426914.2011.610078

[28] Khrisna, P. Vamsi. "Effectiveness of Vegetable Oil based Nanofluids in Machining of Steel." Asian Journal of Multidisciplinary Studies 2, no. 1 (2019).

[29] Yuan, Songmei, Xuebo Hou, Li Wang, and Bochuan Chen. "Experimental investigation on the compatibility of nanoparticles with vegetable oils for nanofluid minimum quantity lubrication machining." Tribology Letters 66, no. 3 (2018): 106.

https://doi.org/10.1007/s11249-018-1059-1

[30] Jamil, Muhammad, Aqib Mashood Khan, Hussien Hegab, Le Gong, Mozammel Mia, Munish K. Gupta, and Ning He. "Effects of hybrid Al 2 O 3-CNT nanofluids and cryogenic cooling on machining of Ti-6Al-4V." The International Journal of Advanced Manufacturing Technology 102, no. 9-12 (2019): 3895-3909. https://doi.org/10.1007/s00170-019-03485-9

[31] Benardos, P. G., and G-C. Vosniakos. "Predicting surface roughness in machining: a review." International journal of machine tools and manufacture 43, no. 8 (2003): 833-844.

https://doi.org/10.1016/S0890-6955(03)00059-2

[32] Vasu, Velagapudi, and K. Manoj Kumar. "Analysis of nanofluids as cutting fluid in grinding EN-31 steel." Nano-Micro Letters 3, no. 4 (2011): 209-214. https://doi.org/10.1007/BF03353674

[33] Sharma, Anuj Kumar, Arun Kumar Tiwari, Rabesh Kumar Singh, and Amit Rai Dixit. "Tribological investigation of TiO2 nanoparticle based cutting fluid in machining under minimum quantity lubrication (MQL)." Materials Today: Proceedings 3, no. 6 (2016): 2155-2162. https://doi.org/10.1016/i.matpr.2016.04.121

[34] Sharma, Puneet, Balwinder Singh Sidhu, and Jagdeep Sharma. "Investigation of effects of nanofluids on turning of AISI D2 steel using minimum quantity lubrication." Journal of cleaner production 108 (2015): 72-79. https://doi.org/10.1016/i.jclepro.2015.07.122

[35] Roy, Sougata, and Amitava Ghosh. "High speed turning of AISI 4140 steel using nanofluid through twin jet SQL system." In ASME 2013 International Manufacturing Science and Engineering Conference collocated with the 41st 
North American Manufacturing Research Conference. American Society of Mechanical Engineers Digital Collection, 2013.

https://doi.org/10.1115/MSEC2013-1067

[36] Kadirgama, K., K. Anamalai, K. Ramachandran, D. Ramasamy, M. Samykano, A. Kottasamy, and M. M. Rahman. "Thermal analysis of SUS 304 stainless steel using ethylene glycol/nanocellulose-based nanofluid coolant." The International Journal of Advanced Manufacturing Technology 97, no. 5-8 (2018): 2061-2076. https://doi.org/10.1007/s00170-018-2061-3

[37] Gupta, Munish Kumar, P. K. Sood, and Vishal S. Sharma. "Optimization of machining parameters and cutting fluids during nano-fluid based minimum quantity lubrication turning of titanium alloy by using evolutionary techniques." Journal of Cleaner Production 135 (2016): 1276-1288.

https://doi.org/10.1016/i.jclepro.2016.06.184

[38] Kulkarni, Harshit B., Mahantesh M. Nadakatti, Sachin C. Kulkarni, and Raviraj M. Kulkarni. "Investigations on effect of nanofluid based minimum quantity lubrication technique for surface milling of Al7075-T6 aerospace alloy." Materials Today: Proceedings (2019).

https://doi.org/10.1016/i.matpr.2019.10.127

[39] Mahadi, M. A., I. A. Choudhury, M. Azuddin, and Y. Nukman. "Use of boric acid powder aided vegetable oil lubricant in turning AISI 431 steel." Procedia engineering 184 (2017): 128-136.

https://doi.org/10.1016/j.proeng.2017.04.077

[40] Sharma, Anuj Kumar, Rabesh Kumar Singh, Amit Rai Dixit, and Arun Kumar Tiwari. "Characterization and experimental investigation of Al2O3 nanoparticle based cutting fluid in turning of AISI 1040 steel under minimum quantity lubrication (MQL)." Materials Today: Proceedings 3, no. 6 (2016): 1899-1906.

https://doi.org/10.1016/i.matpr.2016.04.090

[41] Karandikar, Jaydeep. "Machine learning classification for tool life modeling using production shop-floor tool wear data." Procedia Manufacturing 34 (2019): 446-454

https://doi.org/10.1016/j.promfg.2019.06.192

[42] Yıldırım, Çağrı Vakkas, Murat Sarıkaya, Turgay Kıvak, and Şenol Şirin. "The effect of addition of hBN nanoparticles to nanofluid-MQL on tool wear patterns, tool life, roughness and temperature in turning of Ni-based Inconel 625." Tribology International 134 (2019): 443-456.

https://doi.org/10.1016/j.triboint.2019.02.027

[43] Watmon, Titus B., and Anthony C. Ijeh. "Coating Cutting Tools with Hard Substance Lowers Friction Co-efficient and Improves Tool Life- A Review." In World Congress on Engineering 2012. July 4-6, 2012. London, UK., vol. 2182, pp. 1695-1697. International Association of Engineers, 2010.

[44] Vázquez, K. D., D. S. Cantú, A. F. Segura, F. Araiz, L. Peña-Parás, and D. Maldonado. "Application of Nanofluids to improve tool life in machining processes." Proceedings of the LUBMAT (2014): 1-8.

[45] Minh, Duc Tran, Long Tran The, and Ngoc Tran Bao. "Performance of Al2O3 nanofluids in minimum quantity lubrication in hard milling of 60Si2Mn steel using cemented carbide tools." Advances in Mechanical Engineering 9 , no. 7 (2017): 1687814017710618.

https://doi.org/10.1177/1687814017710618

[46] Sharma, Anuj Kumar, Jitendra Kumar Katiyar, Shubrajit Bhaumik, and Sandipan Roy. "Influence of alumina/MWCNT hybrid nanoparticle additives on tribological properties of lubricants in turning operations." Friction 7, no. 2 (2019): 153-168. https://doi.org/10.1007/s40544-018-0199-5

[47] Lü, Zhijie, Lili Deng, Qingbo Tian, and Xiaoli Zhao. "Cutting performance of Si 3 N 4/TiC micro-nanocomposite ceramic tool in dry machining of hardened steel." The International Journal of Advanced Manufacturing Technology 95, no. 9-12 (2018): 3301-3307.

https://doi.org/10.1007/s00170-017-1259-0

[48] Eltaggaz, A., H. Hegab, I. Deiab, and H. A. Kishawy. "Hybrid nano-fluid-minimum quantity lubrication strategy for machining austempered ductile iron (ADI)." International Journal on Interactive Design and Manufacturing (IJIDeM) 12, no. 4 (2018): 1273-1281.

https://doi.org/10.1007/s12008-018-0491-7

[49] Singh, Rupinder, Jasminder Singh Dureja, Manu Dogra, Munish Kumar Gupta, and Mozammel Mia. "Influence of graphene-enriched nanofluids and textured tool on machining behavior of Ti-6Al-4V alloy." The International Journal of Advanced Manufacturing Technology 105, no. 1-4 (2019): 1685-1697. https://doi.org/10.1007/s00170-019-04377-8

[50] Muthusamy, Y., K. Kadirgama, M. M. Rahman, D. Ramasamy, and K. V. Sharma. "Wear analysis when machining AISI 304 with ethylene glycol/TiO 2 nanoparticle-based coolant." The International Journal of Advanced Manufacturing Technology 82, no. 1-4 (2016): 327-340. 
https://doi.org/10.1007/s00170-015-7360-3

[51] Xavior, M. Anthony, and M. Adithan. "Determining the influence of cutting fluids on tool wear and surface roughness during turning of AISI 304 austenitic stainless steel." Journal of materials processing technology 209, no. 2 (2009): 900-909. https://doi.org/10.1016/i.jmatprotec.2008.02.068

[52] Shao, H., L. Liu, and H. L. Qu. "Machinability study on 3\% Co-12\% Cr stainless steel in milling." Wear 263, no. 1-6 (2007): 736-744. https://doi.org/10.1016/i.wear.2007.01.074

[53] Altin, Abdullah, M. Nalbant, and A. Taskesen. "The effects of cutting speed on tool wear and tool life when machining Inconel 718 with ceramic tools." Materials \& design 28, no. 9 (2007): 2518-2522.

https://doi.org/10.1016/i.matdes.2006.09.004

[54] Ganeshkumar, S., V. Thirunavukkarasu, R. Sureshkumar, S. Venkatesh, and T. Ramakrishnan. "Investigation of wear behaviour of silicon carbide tool inserts and titanium nitride coated tool inserts in machining of en8 steel." International Journal of Mechanical Engineering and Technology 10, no. 01 (2019): 1862-1873.

[55] Sahoo, Rashmi Ranjan, Santu Bhattacharjee, and Tuhin Das. "Development of nanofluids as lubricant to study friction and wear behavior of stainless steels." In International Journal of Modern Physics: Conference Series, vol. 22, pp. 664-669. World Scientific Publishing Company, 2013.

https://doi.org/10.1142/S2010194513010829

[56] Sharma, Anuj Kumar, Rabesh Kumar Singh, Amit Rai Dixit, Arun Kumar Tiwari, and Mahip Singh. "An Investigation on Tool Flank Wear Using Alumina/MoS 2 Hybrid Nanofluid in Turning Operation." In Advances in Manufacturing Engineering and Materials, pp. 213-219. Springer, Cham, 2019.

https://doi.org/10.1007/978-3-319-99353-9 23

[57] Das, Anshuman, Omprakash Pradhan, Saroj Kumar Patel, Sudhansu Ranjan Das, and Bibhuti Bhusan Biswal. "Performance appraisal of various nanofluids during hard machining of AISI 4340 steel." Journal of Manufacturing Processes 46 (2019): 248-270. https://doi.org/10.1016/i.jmapro.2019.07.023

[58] Thamizhmanii, S., and S. Hasan. "Analyses of roughness, forces and wear in turning gray cast iron." Journal of achievements in materials and manufacturing engineering 17, no. 1-2 (2006): 401-404.

[59] Li, Guangxian, Shuang Yi, Nan Li, Wencheng Pan, Cuie Wen, and Songlin Ding. "Quantitative analysis of cooling and lubricating effects of graphene oxide nanofluids in machining titanium alloy Ti6Al4V." Journal of Materials Processing Technology 271 (2019): 584-598. https://doi.org/10.1016/j.jmatprotec.2019.04.035

[60] Abbas, Adel Taha, Munish Kumar Gupta, Mahmoud S. Soliman, Mozammel Mia, Hussein Hegab, Monis Luqman, and Danil Yurievich Pimenov. "Sustainability assessment associated with surface roughness and power consumption characteristics in nanofluid MQL-assisted turning of AISI 1045 steel." The International Journal of Advanced Manufacturing Technology 105, no. 1-4 (2019): 1311-1327.

https://doi.org/10.1007/s00170-019-04325-6

[61] Krajnik, Peter, F. Pusavec, and Amir Rashid. "Nanofluids: properties, applications and sustainability aspects in materials processing technologies." In Advances in sustainable manufacturing, pp. 107-113. Springer, Berlin, Heidelberg, 2011. https://doi.org/10.1007/978-3-642-20183-7 16

[62] Weinert, Klaus, Ichiro Inasaki, J. W. Sutherland, and Toshiaki Wakabayashi. "Dry machining and minimum quantity lubrication." CIRP annals 53, no. 2 (2004): 511-537. https://doi.org/10.1016/S0007-8506(07)60027-4 